\title{
Digital Control of an AC/DC Converter using the Power Balance Control Technique with Average Output Voltage Measurement
}

\author{
Pisit Wisutmetheekorn ${ }^{\dagger}$ and Viboon Chunkag* \\ $\dagger *$ Dept. of Electrical Eng., King Mongkut's University of Technology North Bangkok, Bangkok, Thailand
}

\begin{abstract}
This paper presents a method for the digital control of a high power factor AC/DC converter employing the power balance control technique to achieve a fast response of the output voltage control. To avoid the effects of an output voltage ripple in the voltage control loop, the average output voltage is sampled and used as a feedback signal for the output voltage controller. The proposed control technique was verified by simulations using MATLAB/Simulink and its implementation was realized by a dsPIC30F4011 digital signal processor to control a CUK topology AC/DC converter with a 48V output voltage and a $250 \mathrm{~W}$ output power. The experimental results agree with the simulation results. The proposed control technique achieves a fast transient response with a lower line current distortion than is achieved when using a conventional proportional-integral controller and the power balance control technique with the conventional sampling method.
\end{abstract}

Key Words: AC/DC converter, Digital Control, Power factor correction

\section{INTRODUCTION}

The switched mode dc power supply is an important piece of equipment that provides a dc power source for an electronic circuit in many systems such as in computers, telecommunications, medical equipment and industrial control systems. Normally the input of a switching mode power supply consists of a diode bridge rectifier for converting ac voltage to dc voltage which is then used as the input of the DC/DC converter. The output voltage of the DC/DC converter is regulated to a desired voltage level. To avoid the harmonic currents that are generated by a simple diode bridge rectifier a power factor correction (PFC) circuit is used instead of the diode bridge rectifier. PFC circuits can be divided in to passive and active PFC circuits. The passive type is usually used in a low power applications due to the penalties of weight and size of the passive components that are used in the circuits which must have a high value to comply with the harmonics current regulations. The active type PFC circuit is derived from the conventional switching mode DC/DC converter. Converter topology selection is based on the application requirements such as the voltage conversion ratio, the isolation between the utility and the load, and the difficulty in smoothening the input current. The PFC circuits

Manuscript received Oct. 8, 2010; revised Oct. 11, 2011

Recommended for publication by Associate Editor Byung-Cho Choi.

$\uparrow$ Corresponding Author: s5010190048@kmutnb.ac.th

Tel: +66-2-587-4351, King Mongkut's Univ. of Tech., North Bangkok

* Dept. of Electrical Eng., King Mongkut's University of Technology North

Bangkok, Thailand in [1]-[7] operate in both the continuous conduction mode (CCM) and in the discontinuous conduction mode (DCM). Moreover boundary conduction mode (BCM) PFC circuits have been presented in [8]-[10]. The main advantage of the CCM PFC circuit is its lower peak input current when compared to the DCM and BCM PFC circuits at the same power level. However in the DCM and BCM PFC circuits, only an output voltage control loop is required. For the CCM PFC circuit the control loops are the input current control and the output voltage control as an inner loop and an outer loop, respectively. The response of the current loop control for the CCM PFC circuit should be fast enough to force the input current to follow the input ac voltage waveform for high power factor purposes. To avoid line current distortion in the CCM PFC circuit, the system crossover frequency in the voltage loop should be between $10-20 \mathrm{~Hz}(50 \mathrm{~Hz}$ line frequency) [11]. According to the low crossover frequency, the transient response of the PFC circuit is limited especially under the step-load condition. Methods to improve the dynamic response of the PFC circuit have been proposed. Output voltage ripple cancellation has been presented in [12]-[15], for eliminating the voltage ripple from the error signal of the voltage loop and for improving the output voltage control response. However the filter design is complex and the implementation requires a fast digital controller such as a high speed digital signal processor (DSP) or a field programmable gate array (FPGA) platform. A simple control technique has been proposed in [16]. This method is based on load current feedforward and the concept of input-output power balance. However, with this 
method, a voltage ripple occurs in the voltage control loop and it causes a distortion in the input current waveform. This paper presents a control method for an AC/DC converter. The input-output power balance concept and the average output voltage sampling method are used as control strategies. The proposed sampling method is used to eliminate the effects of the voltage ripple in the control loop. A load current transducer is used in the proposed method. Moreover it can be used for active current sharing purposes when multiple converters are connected in parallel for a high power applications. The proposed control method is demonstrated on a $250 \mathrm{~W}$ CUK $\mathrm{AC} / \mathrm{DC}$ converter and the control algorithm is implemented with a low cost DSP (dsPIC30F4011 from Microchip). The advantages of the digital control system over an analog control implementation include a lower sensitivity to environmental variations, ease of changing the control algorithm by updating the control firmware in the programmable memory of the processor, and the fact that the system can communicate with other parallel connected modules by using the built in serial communication. Load current sharing and redundancy operation in the modular approach AC/DC converter can be performed.

\section{The Proposed System AND SAMPLING METHOD}

Fig. 1 shows the proposed system including the control algorithm. The CUK topology AC/DC converter has inductors at the both ends of the circuit. As a result, the input and output current of the converter can be continuous, and the input current is easily controlled to be sinusoidal as the input line voltage. The CUK AC/DC converter is designed to operate in the CCM mode and the input inductor current is controlled by a simple analog circuit which is a hysteresis current controller. A zero crossing detector (ZCD) circuit is used to detect the zero crossing point $\left(0^{\circ}\right)$ of the input ac line voltage. The output signal of the ZCD circuit is used to interrupt the dsPIC30F4011 DSP by feeding this signal to the INT0 pin. When the output signal of the ZCD circuit is changed from $0 \mathrm{~V}$ (logic ' 0 ') to $5 \mathrm{~V}$ (logic ' 1 '), an INT0 interrupt occurs. After that the interrupt service routine (ISR) for the INT0 interrupt is active and the variable in the software counter block is cleared to zero. The value of the software counter is increased by 1 every $200 \mu \mathrm{s}$. A time base with a $200 \mu$ s time interval is generated by the internal timer of the dsPIC30F4011 and this time base is also used as a sampling period for the digital controller that is used to regulate the output voltage of the converter. The A/D blocks in Fig. 1 are the internal analog to digital converters of the dsPIC30F4011 and the resolution is 10 bit with a $5 \mathrm{~V}$ maximum input voltage. Three internal analog to digital converters are used in the proposed system. The D/A is a digital to analog converter circuit that is used to convert the digital control signal in to an analog signal. The analog signal from the D/A is a command which is used to control the input inductor current $i_{L 1}$ of the CUK converter. From the input-output power balance concept, if the input line currenti $i_{S}$ is controlled to be sinusoidal and in phase with the line voltage, the input and the output power equations of the circuit can be written as in (1)-(2).

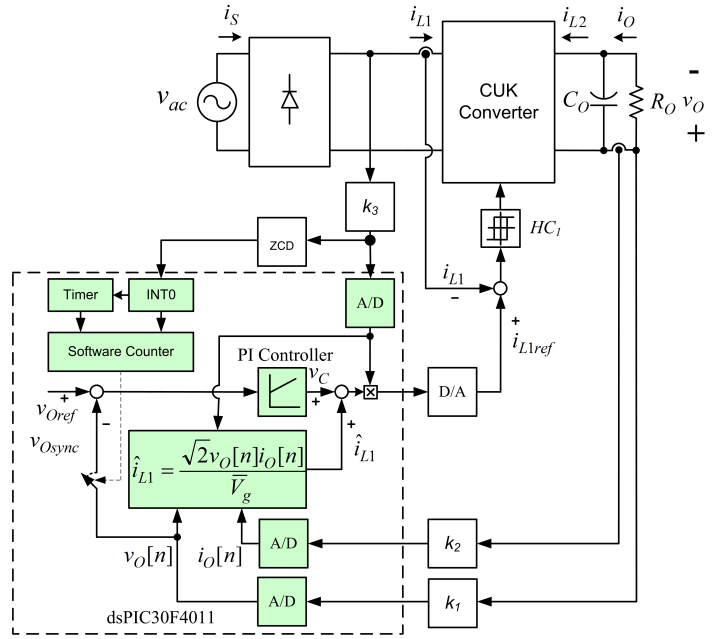

Fig. 1. Diagram of the proposed system.

$$
\begin{gathered}
p_{\text {out }}(t)=\eta \cdot p_{\text {in }}(t) \\
P_{\text {out }}(t)=\eta \cdot \hat{V}_{g} \sin (\omega t) \cdot \hat{I}_{s} \sin (\omega t)
\end{gathered}
$$

where $\hat{V}_{g}, \hat{I}_{s}$ and $\eta$ are the peak value of the line voltage, the peak value of the input current and the efficiency of the converter, respectively. Rearrange (2) and the output power can be written as shown in (3).

$$
P_{\text {out }}(t)=\eta \cdot V_{g} \cdot I_{S}(1-\cos (2 \omega t))
$$

where $V_{g}$ and $I_{s}$ are the rms value of the input ac line voltage and the input current of the AC/DC converter. From (3) the output power consists of two terms but the average output power is equal to the dc term of (3). The inductor current $i_{L 2}$ can be calculated by dividing (3) by the average output voltage $\bar{V}_{o}$. Therefore, the output inductor current can be written as in (4) and the ac component of this current is the capacitor currenti $i_{C o}(t)$ as in (5).

$$
\begin{gathered}
i_{L 2}(t)=\frac{\eta \cdot V_{g} \cdot I_{s}}{\bar{V}_{o}}(1-\cos (2 \omega t))=I_{o}-\frac{\eta \cdot V_{g} \cdot I_{s}}{\bar{V}_{o}} \cos (2 \omega t) \\
i_{C o}(t)=\frac{\eta \cdot V_{g} \cdot I_{s}}{\bar{V}_{o}} \cos (2 \omega t)
\end{gathered}
$$

From the output capacitor current, the instantaneous value of the output voltage can be obtained by integrating the output capacitor current in (5). The output voltage ripple can be written as in (6)-(7).

$$
\begin{aligned}
& v_{\text {ripple }}(t)=\frac{1}{C_{o}} \int \frac{\eta \cdot V_{g} \cdot I_{s}}{\bar{V}_{o}} \cos (2 \omega t) d t \\
& v_{\text {ripple }}(t)=\frac{\eta \cdot V_{g} \cdot I_{s}}{2 \cdot \omega \cdot C_{o} \cdot \bar{V}_{o}} \sin (2 \omega t+\pi)
\end{aligned}
$$

where $v_{\text {ripple }}$ is the output voltage ripple of the converter and $\bar{V}_{o}$ is the average value of the output voltage. From the output voltage ripple in (7), it can be seen that the voltage ripple runs at twice the line frequency and that the magnitude of the voltage ripple is zero at the zero crossing point of the line voltage. Thus the average output voltage can be measured by reading the output voltage at the zero crossing point of 

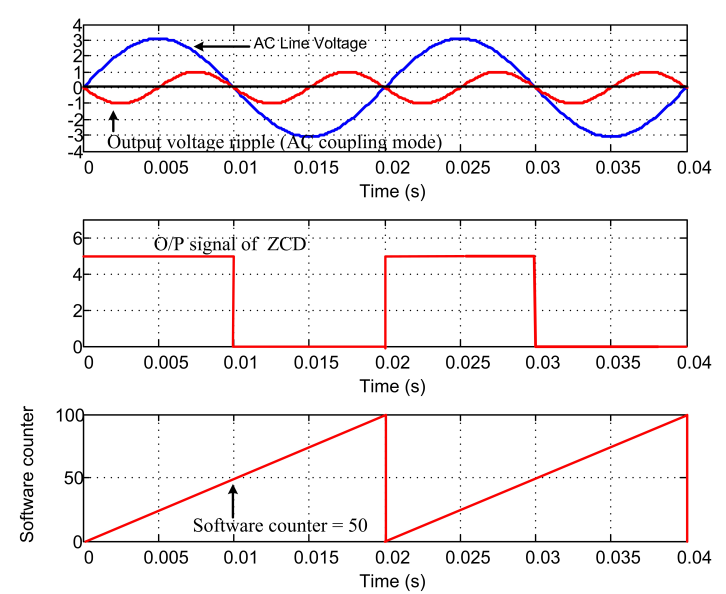

Fig. 2. Waveforms of line voltage, output voltage ripple, output of the zero crossing detector circuit and value of software counter.

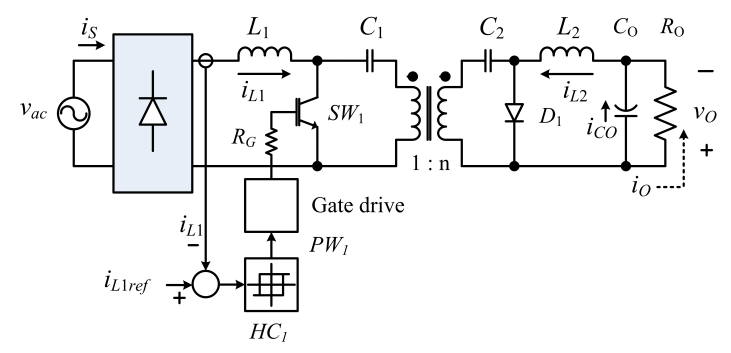

Fig. 3. The power circuit of the CUK AC/DC converter.

the input line voltage of the converter. From the relation between the output voltage ripple waveform and the input line voltage waveform, the output voltage should be sampled by the internal analog to digital converter of the DSP at the zero crossing point of the ac line voltage waveform. Therefore a timing diagram of the output voltage sampling process can be drawn as shown in Fig. 2. The variable $v_{\text {Osync }}$, in Fig. 1, is obtained by updating the output voltage sensed at the zero crossing point of the ac line voltage. The variablevoref is the output voltage command.

Fig. 3 shows the converter power circuit. A high frequency transformer is inserted in a conventional CUK converter to isolate the load and the ac voltage source for safety and voltage scaling reasons. The parameters of the circuit are determined by the calculation method presented in [17]. The parameters of the power circuit used in this paper are shown in Table I.

\section{Transfer Function And Controller Design}

The transfer function of a power converter should be determined prior designing and calculating the controller parameters. By using the average small signal analysis to find a transfer function of the power converter, the dynamic equation at the output node of the power circuit in Fig. 3 can be written as in (8).

$$
i_{L 2}=C_{O} \frac{d v_{O}}{d t}+i_{O}
$$

Using the input and output power balance concept, the relationship between both of the inductor currents can be written as in (9).

$$
i_{L 2} \cdot v_{O}=\frac{i_{L 1} \cdot V_{g}}{\sqrt{2}} .
$$

TABLE I

THE CUK CONVERTER SPECIFICATIONS

\begin{tabular}{|l|l|}
\hline Input Voltage & $220 \mathrm{~V} / 50 \mathrm{~Hz}$ \\
\hline Output Voltage & $48 \mathrm{~V}$ \\
\hline Power & $250 \mathrm{~W}$ \\
\hline$C_{1}=C_{2}$ & $0.68 \mu \mathrm{F}$ \\
\hline$L_{1}, L_{2}$ & $5 \mathrm{mH}, 1 \mathrm{mH}$ \\
\hline$C_{O}$ & $23600 \mu \mathrm{F}$ \\
\hline
\end{tabular}

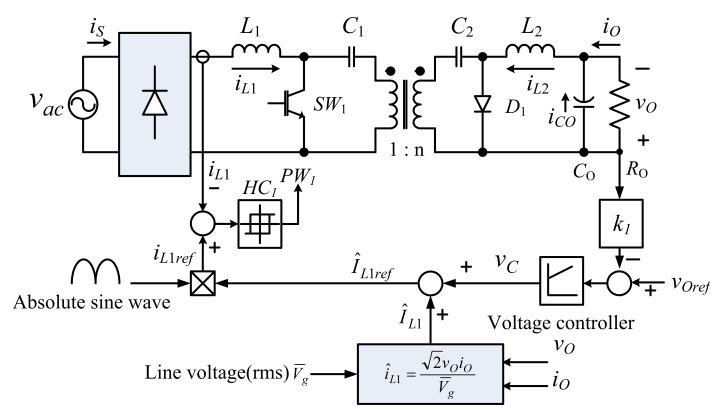

Fig. 4. CUK AC/DC converter controlled by the PI controller with the power balance control technique.

By considering the input and output power balance in a half line cycle, the peak value of the input inductor current $\hat{i}_{L 1}$ can be written as in (10).

$$
\hat{i}_{L 1}=\frac{\sqrt{2} \cdot i_{\text {load }} \cdot v_{O}}{V_{g}} .
$$

The control loop of the AC/DC converter employs a proportional-integral (PI) controller with the power balance control technique, as shown in Fig. 4. The magnitude of the input inductor current command is obtained by adding the control signal $v_{C}$ of the output voltage controller and the current $\hat{i}_{L 1}$, which is calculated from the power balance concept. Therefore, the magnitude of the input inductor current command can be written as in (11).

$$
\hat{I}_{L 1 r e f}=\hat{i}_{L 1}+v_{C} .
$$

A PI controller is chosen to control the output voltage, and the continuous-time PI controller transfer function is shown in (12).

$$
G_{C}(s)=K_{P}+\frac{K_{I}}{s}
$$

where $K_{P}$ is the proportional gain and $K_{I}$ is the integral gain of the continuous-time PI controller. After applying a perturbation, the small signal approximation method is used on (8)-(11). Then the results are then shown in (13)-(16).

$$
\begin{gathered}
\tilde{v}_{O}=\frac{\tilde{i}_{L 2}-\tilde{i}_{\text {Load }}}{C_{O S}} \\
\tilde{i}_{L 2}=\frac{V_{g}}{\sqrt{2} \cdot \bar{V}_{O}} \cdot \tilde{\hat{I}}_{L 1}+\frac{\bar{I}_{L 1}}{\sqrt{2} \cdot \bar{V}_{O}} \cdot \tilde{v}_{g}-\frac{\bar{I}_{L 2}}{\bar{V}_{O}} \cdot \tilde{v}_{O} \\
\tilde{i}_{L 1}=\frac{\sqrt{2} \bar{I}_{\text {Load }}}{V_{g}} \cdot \tilde{v}_{O}+\frac{\sqrt{2} \bar{V}_{O}}{V_{g}} \cdot \tilde{i}_{\text {Load }}-\frac{\bar{I}_{L 1}}{\sqrt{2} V_{g}} \cdot \tilde{v}_{g} \\
\tilde{\hat{I}}_{L 1 \text { ref }}=\tilde{\hat{i}}_{L 1}+\tilde{v}_{C} .
\end{gathered}
$$

From (13)-(16), the variables with the sign '-' are the steady state values and the variables with the sign " $\sim$ are the small signal values. From (13)-(16), a block diagram that shows the 
relation between the output voltage and the output voltage command can be drawn. By using the block diagram reduction method, as in classical control theory, the transfer function of the output voltage to the output voltage command can be written as in (17).

$$
\frac{\tilde{v}_{O}}{\tilde{v}_{\text {Oref }}}=\frac{G_{C}(s) V_{g}}{\sqrt{2} \bar{V}_{O} C_{O} s+k_{1} G_{C}(s) V_{g}}
$$

where $k_{1}$ is the feedback gain used to attenuate the voltage from the output node to an appropriate value for the internal analog to digital converter of the dsPIC30F4011. From the closed loop transfer function in (17), the open loop transfer function $G_{P}(s)$ without the controller $G_{C}(s)$ can be written as in (18).

$$
G_{P}(s)=\frac{k_{1} V_{g}}{\sqrt{2} \bar{V}_{O} C_{O} s} .
$$

The controller parameters are chosen by using the frequency response design method. Before calculating the parameters, the frequency responses of the compensated system are specified such as the phase margin value and the crossover frequency. From (18), the phase value of the uncompensated system is $-90^{\circ}$. Then the phase value of the controller is obtained by (19).

$$
\theta_{C}=\frac{\left(90^{\circ}-\theta_{R}\right) \cdot \pi}{180}
$$

where $\theta_{C}$ and $\theta_{R}$ are the controller phase value and the required phase margin of the compensated system. From the controller phase value and the controller transfer function, the controller parameters can be obtained by (20)-(21).

$$
\begin{gathered}
K_{P}=\frac{\cos \left(\theta_{C}\right)}{G_{P O}} \\
K_{I}=\frac{\sin \left(\theta_{C}\right) \cdot 2 \pi f_{C}}{G_{P O}}
\end{gathered}
$$

where $G_{P O}$ is the magnitude of the open loop transfer function $G_{P}(s)$ at the crossover frequency $f_{C}$. After the analog PI controller design is finished, the parameters are used to calculate the control signal of the dsPIC30F4011 DSP by (22).

$$
u(n)=K_{P} \cdot e(n)+K_{I} \cdot T_{s} \sum_{k=1}^{n} e(n)
$$

where $u(n)$ is the output control signal of the digital controller, $e(n)$ is an error signal and $T_{s}$ is a sampling time period.

\section{EfFect of the Output Voltage Ripple in PFC CONTROL}

Regarding the two control loops of the AC/DC converter described earlier, the current controller will force the input current to track the current command. The current command is generated by multiplying an absolute sine wave signal, which is in-phase with the input line voltage, by a control signal from the output voltage controller. The concept of the two control loops of the PFC circuit is shown in the diagram in Fig. 5. The ideal case for the steady state condition is that, the control signal from the voltage loop controller should be a dc signal. Then the resultant signal after multiplication with an absolute sine wave will be an absolute sinusoidal signal with

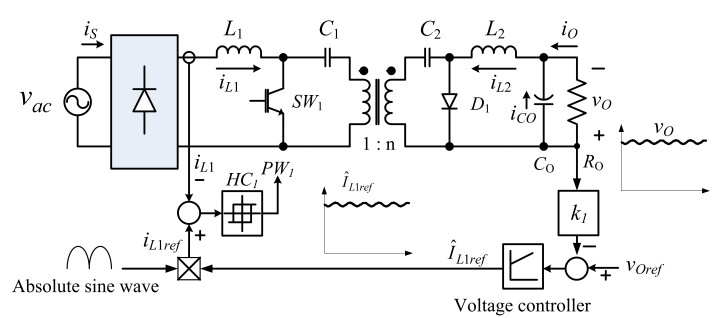

Fig. 5. The Control loop of the AC/DC converter.
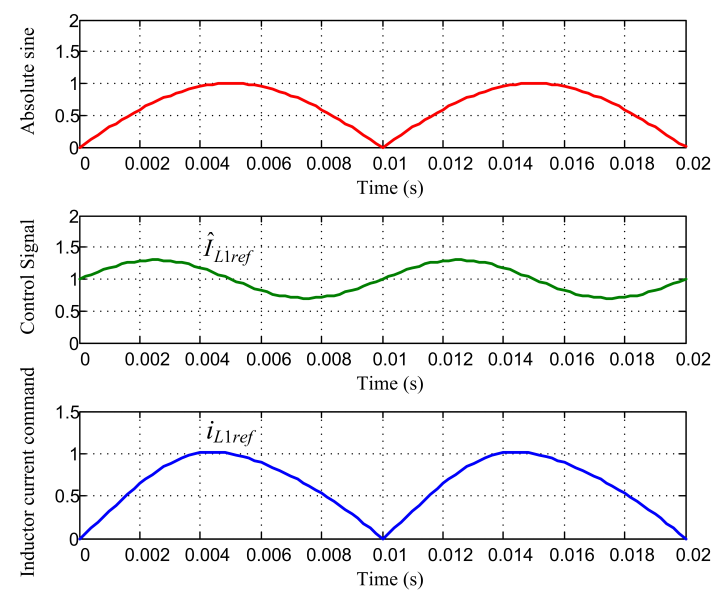

Fig. 6. The distortion of the inductor current command with the ripple voltage on a signal from the voltage controller.

a low level of distortion. However, in practical realization, the control signal from the output voltage controller is not a pure de signal. It also contains a ripple that is affected by the ripple in the output of the power converter. Then the inductor current command of the later case will be a distortion of an ideal sinusoidal wave, as shown in Fig. 6.

The distorted input current of the AC/DC converter is influenced by the voltage ripple in the voltage control loop as discussed in [8] and [17]. However, with the proposed sampling method in this paper, the influence of the output voltage ripple on the voltage control loop is minimized. Because the sampling is always read, the output voltage is at the point when its value is approximately equal to the average value of the output voltage. Then the input current distortion can be reduced.

\section{Simulation Results}

The CUK AC/DC converter is simulated by the MAT$\mathrm{LAB} /$ Simulink simulation program. The converter parameters for the simulation are shown in Table I. The results show the transient response of the output voltage control and the steady state performance of the proposed control method compared with converters that are controlled by a conventional PI controller and a PI controller with the power balance control technique. Fig. 7 and Fig. 8 show the transient response and the steady state response of the CUK AC/DC converter controlled by the digital PI controller with a $200 \mu$ s sampling time period for updating the output voltage value and for calculating the control signal. In Fig. 7, the load is changed from $200 \mathrm{~W}$ to $100 \mathrm{~W}$ and then back to $200 \mathrm{~W}$ at $0.4 \mathrm{~s}$ and $0.7 \mathrm{~s}$, respectively. The settling time in Fig. 7 is $100 \mathrm{~ms}$ while the load changed from $200 \mathrm{~W}$ to $100 \mathrm{~W}$ with a $2.72 \%$ overshoot. Fig. 8 shows 

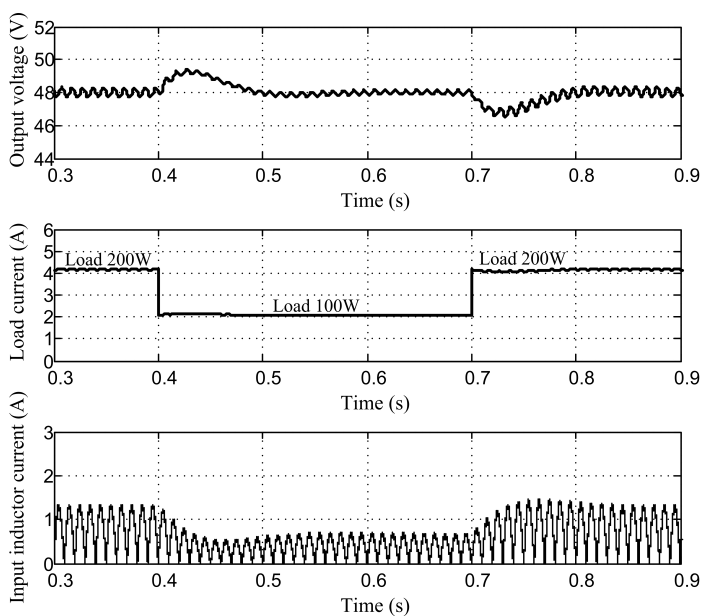

Fig. 7. Simulated transient response of the CUK AC/DC converter controlled by the PI controller with $200 \mu$ ssampling time.

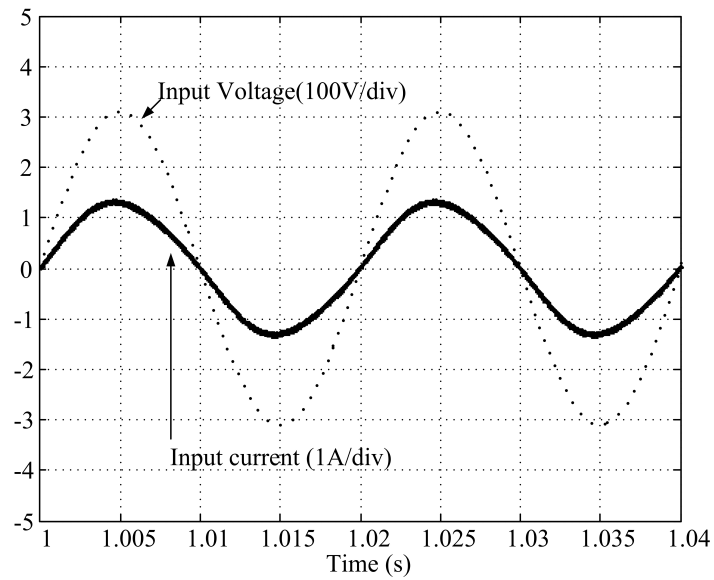

Fig. 8. Simulated steady state response of the CUK AC/DC converter controlled by the PI controller with $200 \mu$ ssampling time.

the input current of the PFC circuit at 200W of output power that is in phase with the input voltage. However, the current distortion still occurred and can be seen in the current spectra as shown in Fig. 9.

The results in Fig. 10 and Fig. 11 show the transient response and the steady state response of the CUK AC/DC converter that is controlled by using the PI controller with the power balance control technique, as shown in Fig. 4. However, the results in Fig. 10 and Fig. 11 are for the conventional sampling method with a $200 \mu$ ssampling time for the controller. The results in Fig. 10 and Fig. 11 show that the load condition is still using a step load from $200 \mathrm{~W}$ to $100 \mathrm{~W}$ and then back to $200 \mathrm{~W}$ at $0.4 \mathrm{~s}$ and $0.7 \mathrm{~s}$, respectively. In Fig. 10 the output voltage is almost constant even when the load power is changed from $200 \mathrm{~W}$ to $100 \mathrm{~W}$ at $0.4 \mathrm{~s}$. From the results, it can be seen that the voltage ripple can be increased by increasing the load current. Fig. 11 shows the steady state response of the input current and input voltage of the AC/DC converter with a $200 \mathrm{~W}$ load.

Fig. 12 is the input current harmonics spectrum of the AC/DC converter. From this result, the $3^{\text {rd }}$ order harmonic of the input current of the AC/DC converter controlled by the PI controller with the power balance control technique is lower than that of the $\mathrm{AC} / \mathrm{DC}$ converter controlled by

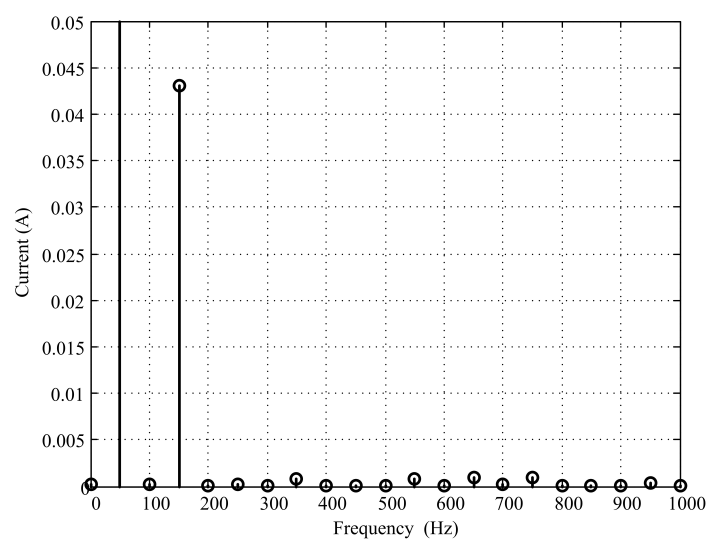

Fig. 9. The harmonics spectrum of the input current in Fig. 8.
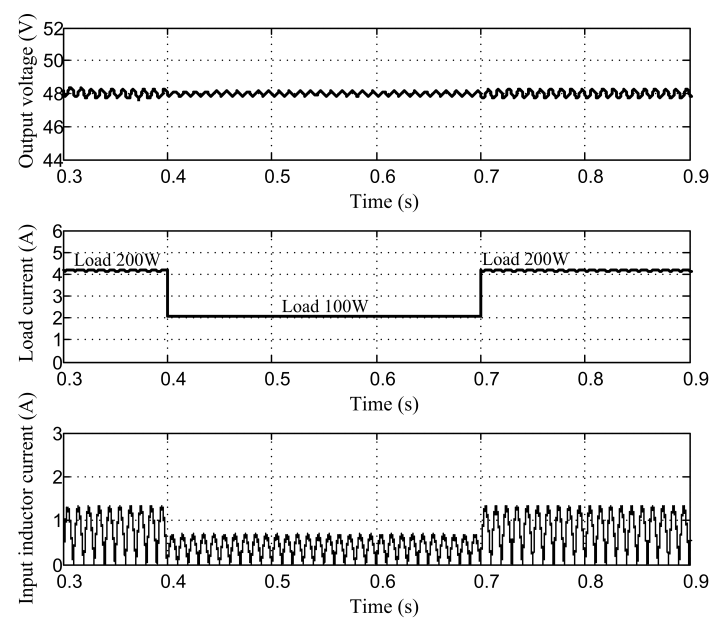

Fig. 10. Simulated transient response of the CUK AC/DC converter controlled by the PI controller with the power balance control technique using 200 $\mu$ ssampling time.

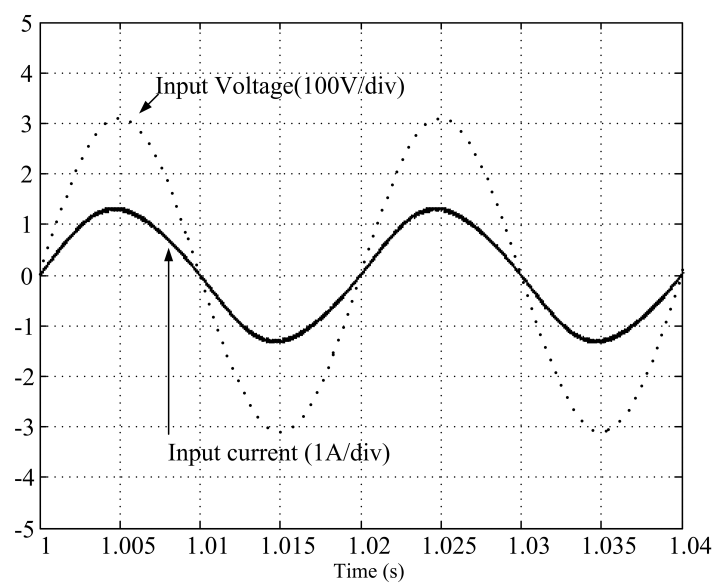

Fig. 11. Simulated steady state input current and voltage of the converter controlled by the PI controller with the power balance control technique and $200 \mu$ ssampling time period. 


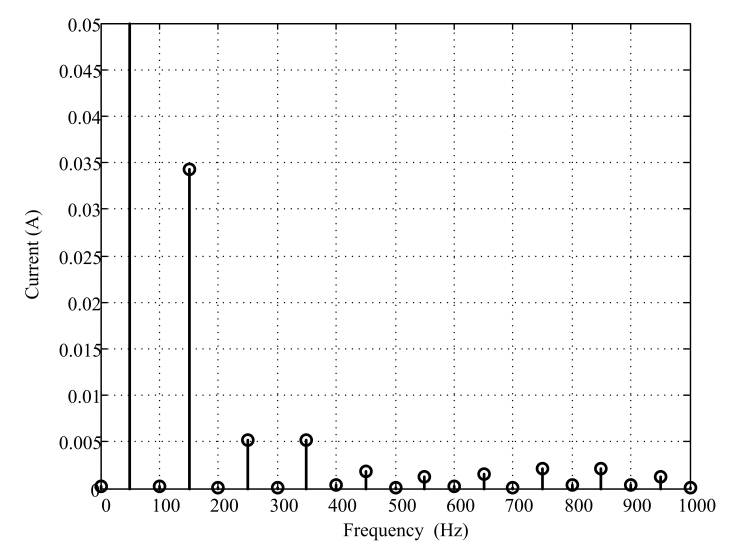

Fig. 12. The harmonics spectrum of the input current in Fig. 11.
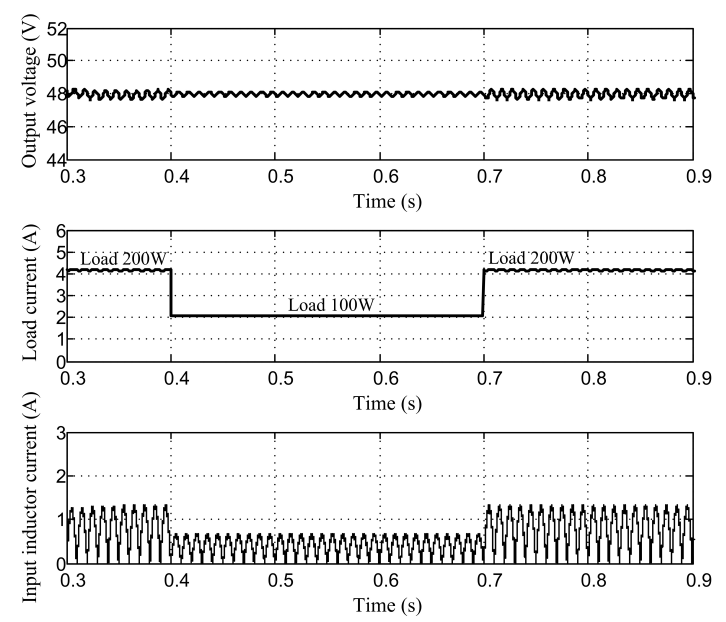

Fig. 13. Simulated transient response of the CUK AC/DC converter controlled by the PI controller with the power balance control technique using the proposed sampling method.

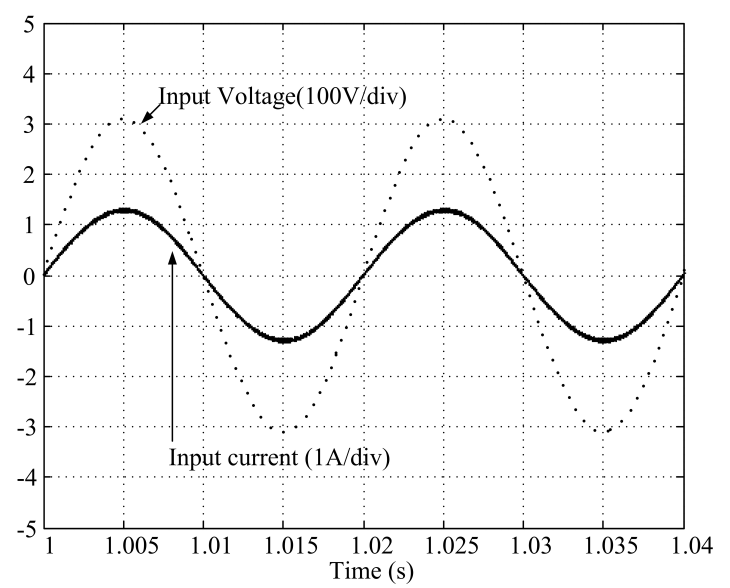

Fig. 14. Simulated steady state input current and voltage of the converter controlled by the proposed control method.

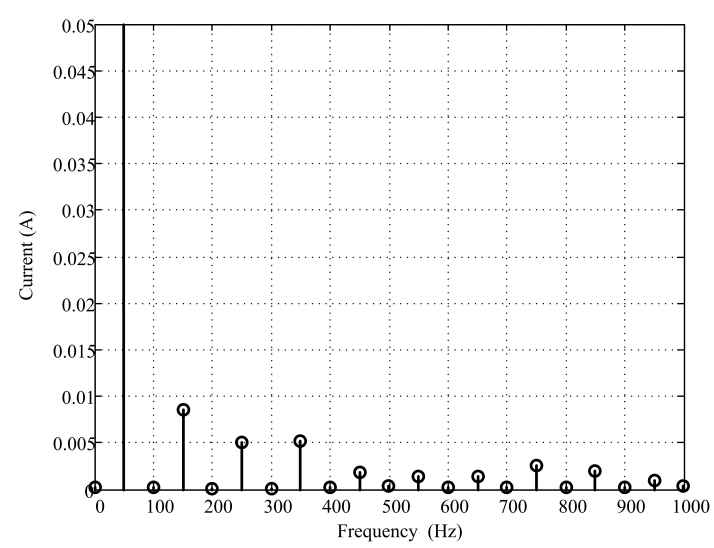

Fig. 15. The harmonics spectrum of the input current in Fig. 14.

the conventional PI controller. Moreover, by using the power balance control technique, the magnitude of the harmonics current at a higher frequency is more than that of the $\mathrm{AC} / \mathrm{DC}$ converter controlled by the PI controller. However, by using both of the voltage control techniques, the occurrence of the harmonics current is still lower than the limit defined in the harmonic regulations. To reduce the distortion of the input current of the AC/DC converter, the proposed sampling method, which senses the average output voltage, is used and the voltage loop is controlled by the PI controller with the power balance control technique for a fast transient response. The simulated transient response and the steady state response of the AC/DC converter controlled by the proposed method are shown in Fig. 13 and Fig. 14. The responses with load changes from $200 \mathrm{~W}$ to $100 \mathrm{~W}$ and from $100 \mathrm{~W}$ to $200 \mathrm{~W}$ are shown in Fig. 13. The response time is as fast as the response time, from Fig. 7, using the PI controller with the power balance control technique and the conventional sampling method. In Fig. 14 the line current has a lower distortion than the input current shown in Fig. 8 and Fig. 11. The harmonics spectrum, as shown in Fig. 15, also confirms that the converter controlled by the proposed method has a lower input current distortion than the converter using the conventional PI controller and the PI controller with the power balance control technique using the conventional sampling method.

\section{EXPERIMENTAL RESULTS}

To confirm the performance of the proposed system an experiment was set up and the results were compared with those of the simulation. The parameters of the CUK AC/DC converter used in the experiment are shown in Table I. Three control strategies were implemented on a dsPIC30F4011 to control the AC/DC converter for performance comparison purposes. The implemented control methods in the experiment are the conventional PI controller, the PI controller with the power balance control technique and the PI controller with the power balance control using average output voltage measurement. The PI controller parameters of these control methods were designed so that the phase margin of the compensated system was $70^{\circ}$ with a $15 \mathrm{~Hz}$ crossover frequency. The proportional gain and the integral gain of the controller are 3.86 and 132.73, respectively. For every control algorithms in the experiment, the sampling time period was set at $200 \mu$ s. However, for the 


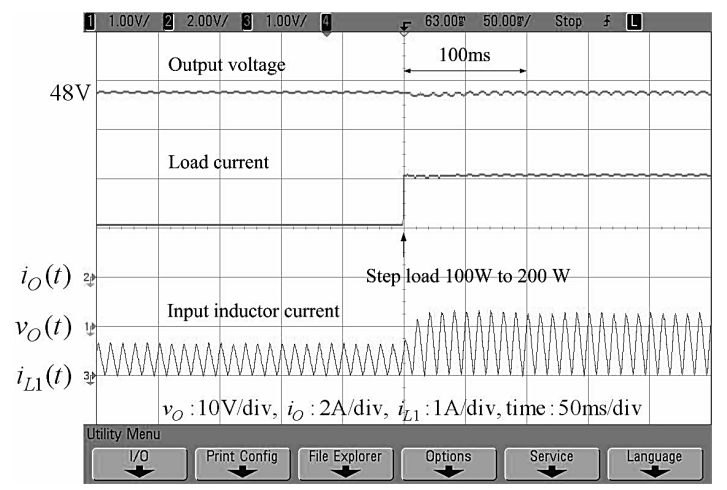

Fig. 16. Transient response of the AC/DC converter controlled by the PI controller.

proposed control algorithm, the output voltage value in the voltage control loop is updated at the zero crossing point of the ac line voltage.

\section{A. Transient Response}

The transient responses of the CUK AC/DC converter controlled by the conventional PI controller are shown in Fig. 16 and Fig. 17. The output voltage, the load current and the input inductor current of the CUK AC/DC converter at a step load from $100 \mathrm{~W}$ to $200 \mathrm{~W}$ are shown in Fig. 16. The response to a step load from $200 \mathrm{~W}$ to $100 \mathrm{~W}$ is shown in Fig. 17. From these results, it can be seen that the settling time is about $100 \mathrm{~ms}$. The overshoot and the undershoot responses are approximately $0.8 \mathrm{~V}$ as can be seen from the responses in Fig. 18. The output voltage waveform in Fig. 18 was measured by using the ac coupling mode of an oscilloscope.

Fig. 19 shows the step response of the CUK AC/DC converter controlled by the PI controller with the power balance control technique using the conventional sampling method. The load condition in Fig. 19 was changed from $100 \mathrm{~W}$ to $200 \mathrm{~W}$ and then back to $100 \mathrm{~W}$. From this result, the AC/DC converter controlled by the PI controller with the power balance control technique has a faster response in voltage control than the one using the conventional PI controller.

As a result of the proposed control method shown in Fig. 1, the sampling time period of the voltage loop is still the same as that of the two previous control algorithms. However, in the proposed method, the average output voltage is used as a feedback signal in the voltage control loop and it is updated by sampling the output voltage at the zero crossing point of the line voltage or the rectified line voltage.

From Fig. 20, the output voltage sensed at the zero crossing point of the rectified line voltage is approximate to the average output voltage. The transient responses of the AC/DC converter controlled by the proposed method are shown in Fig. 21 and Fig. 22. These results show that the proposed control method has as fast a response in voltage control as that of the converter controlled by the PI controller with the power balance control technique. The output voltage control response is very fast and the amplitude of the input inductor current is suddenly changed when the load power is step from $100 \mathrm{~W}$ to 200W.

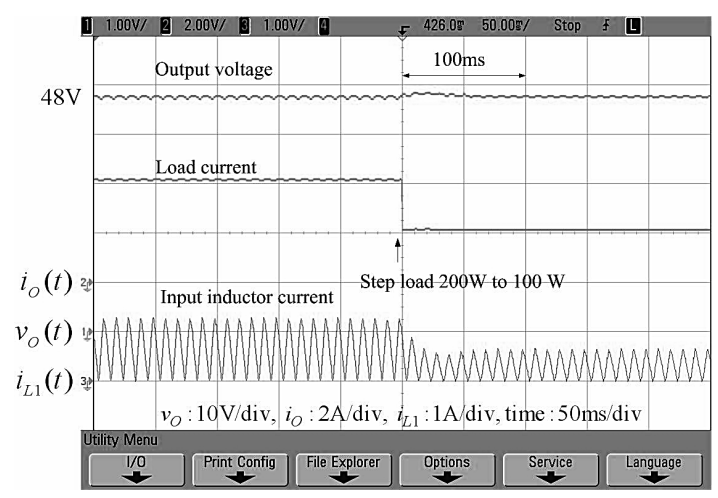

Fig. 17. Transient response with step load at $200 \mathrm{~W}$ to $100 \mathrm{~W}$ of the AC/DC converter controlled by the PI controller.

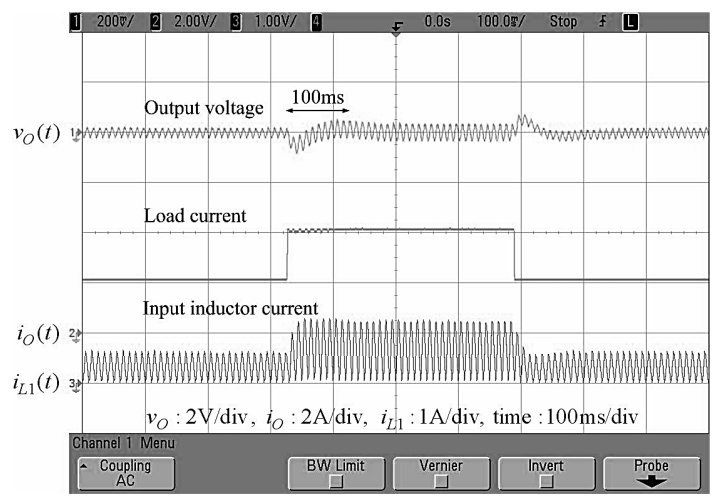

Fig. 18. Transient response of the AC/DC converter controlled by the PI controller.

\section{B. Steady State Response}

In this section, an experiment was carried out to verify the steady state performance of the purposed control method and to compare it with those of the conventional PI controller and the PI controller with power balance control technique. Fig. 23 and Fig. 24 show the steady state response of the AC/DC converter with a $100 \mathrm{~W}$ load controlled by the conventional PI controller. From Fig. 23, the input current of the converter is distorted and the total harmonic distortion (THD) of the current is $10.6 \%$, as can be seen in Fig. 24. By using the PI controller with the power balance control technique to control the converter, the steady state results with a $100 \mathrm{~W}$ load power are shown in Fig.25 and Fig.26. The input current is also distorted and its THD is approximately equal to the THD shown in Fig. 24. For Fig. 27 and Fig. 28 the load condition for the experiment is the same as the conditions for the experiments with the two previous control methods. The steady state input current of the converter controlled by the proposed control method is shown in Fig. 27. The load condition in these results is $100 \mathrm{~W}$ and it is the same value as in the experiments using the two previous control methods. The input current of the converter in Fig. 27 has a lower distortion than the current shown in Fig. 23 and Fig. 25. The THD of the input converter current with a $100 \mathrm{~W}$ load by using the proposed control method is $5.2 \%$. The results, from Fig. 23-Fig. 28, show that the AC/DC CUK converter controlled by the proposed control method has a lower input current distortion than the two previous methods. From the results in Fig. 23-Fig. 26, it can be seen that the input current distortion 


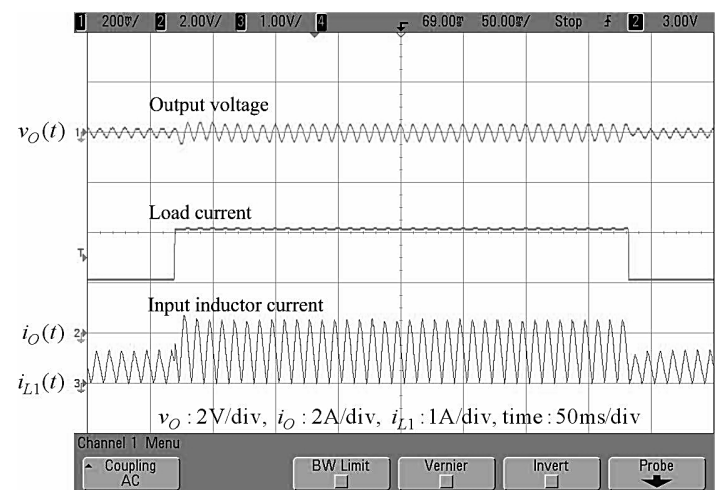

Fig. 19. Transient response of the AC/DC converter controlled by the PI controller with the power balance control technique.

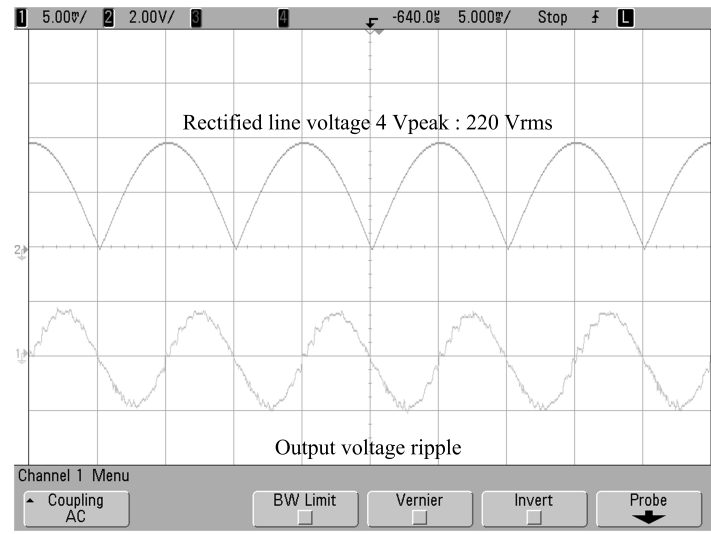

Fig. 20. The waveform of the rectified line voltage and the output voltage ripple of the AC/DC converter(ac coupling mode).

of the converter controlled by the conventional PI controller is as same as that of the CUK AC/DC converter controlled by the PI controller with the power control technique using the conventional sampling method. Using the proposed control scheme, the input current of the AC/DC converter and the harmonics content are shown in Fig. 27 and Fig. 28. These results show that the AC/DC converter controlled by the proposed method has a lower input current distortion than the two previous control methods. In general, the THD of the input current of the PFC circuit is dependent on the load power. However, with the proposed method, the average output voltage is sampled and then the influence of the voltage ripple on the voltage control loop of the PFC circuit is minimized. As a result, the THD of the input current of the AC/DC converter is low even when the load is changed. The input current harmonics of the AC/DC converter controlled by the proposed method at load values of $55 \mathrm{~W}, 150 \mathrm{~W}$ and $200 \mathrm{~W}$ are shown in Fig. 29, Fig. 30 and Fig. 31, respectively.

\section{CONCLUSION}

The control design of a CUK AC/DC converter has been presented. The digital controller was implemented on a dsPIC30F4011 DSP. The nearly average output voltage sampling method has been proposed. By the proposed method, the influence of the output voltage ripple on the control loop of the AC/DC converter is minimized. To investigate the proposed method, simulation and experimental results were obtained. The transient and the steady state performance of

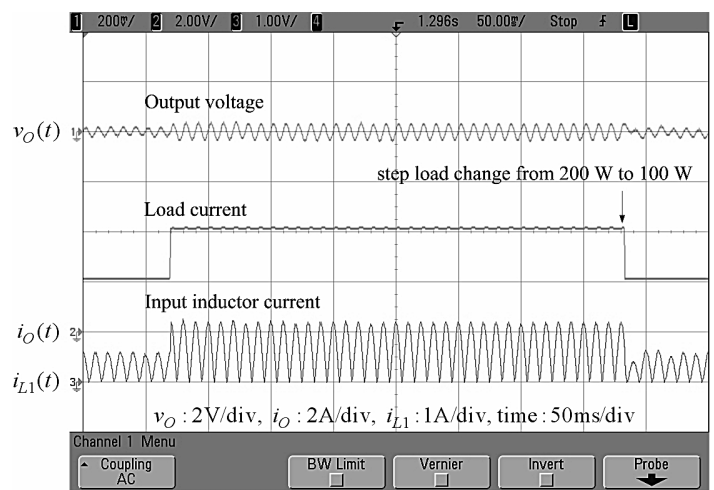

Fig. 21. Transient response of the AC/DC converter controlled by the proposed method.

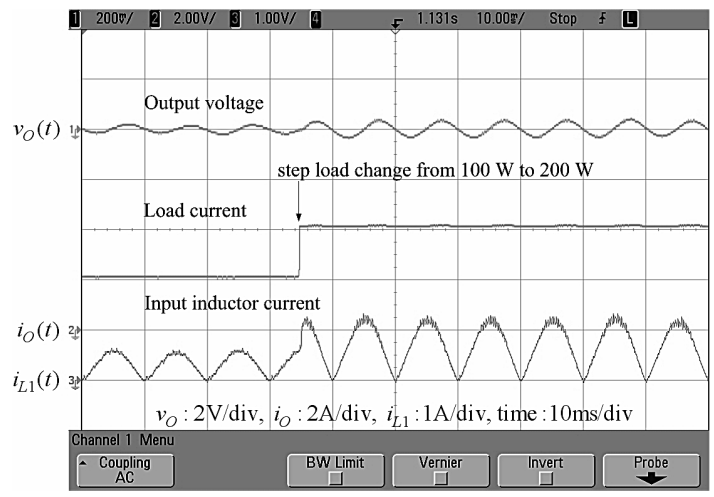

Fig. 22. The closed up waveforms of the signals in Fig. 21.

the CUK AC/DC converter controlled by the proposed method was compared to the CUK AC/DC converter controlled by a conventional PI controller and a PI controller with the power balance control technique using the conventional sampling method. From both the simulation and the experimental results, it can be seen that the proposed method has achieved a fast response in output voltage control and a low THD value of the input current even when the load is varied. Without using an input line filter circuit, the THD of the input current at loads of $55 \mathrm{~W}, 100 \mathrm{~W}, 150 \mathrm{~W}$ and $200 \mathrm{~W}$ are $6.5 \%, 5.2 \%$, $5.2 \%$ and $5.7 \%$, respectively.

\section{ACKNOWLEDGMENT}

This work was supported by the Graduate College and the Faculty of Engineering, King Mongkut's University of Technology North Bangkok (KMUTNB), Bangkok, Thailand. 


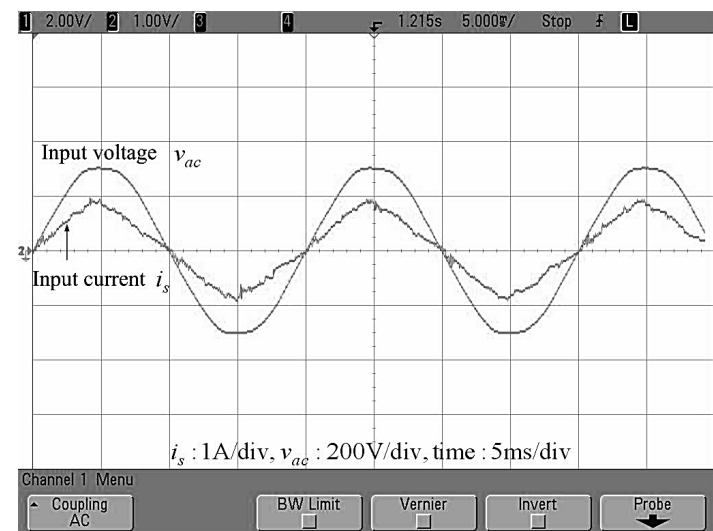

Fig. 23. The steady state input current and input voltage of the AC/DC converter controlled by the PI controller.

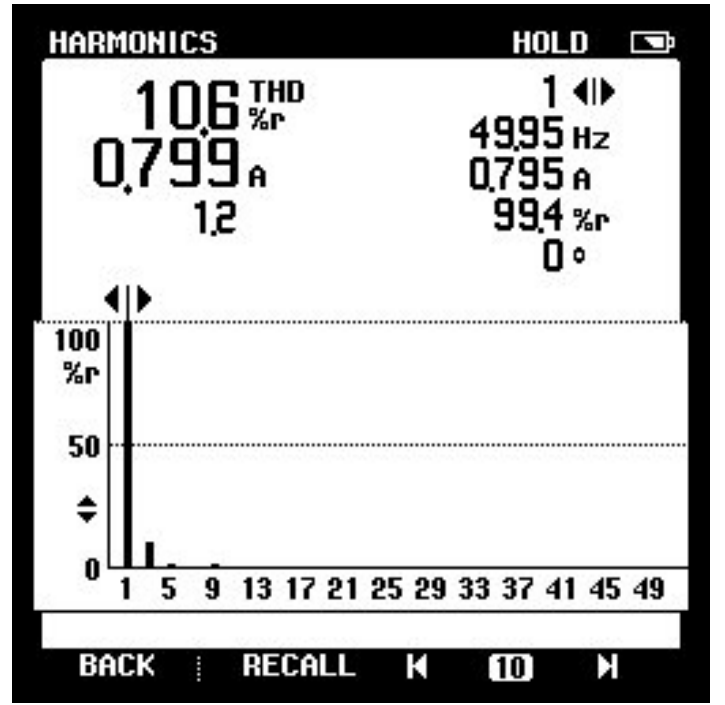

Fig. 24. The harmonics content of the input current in Fig. 23.

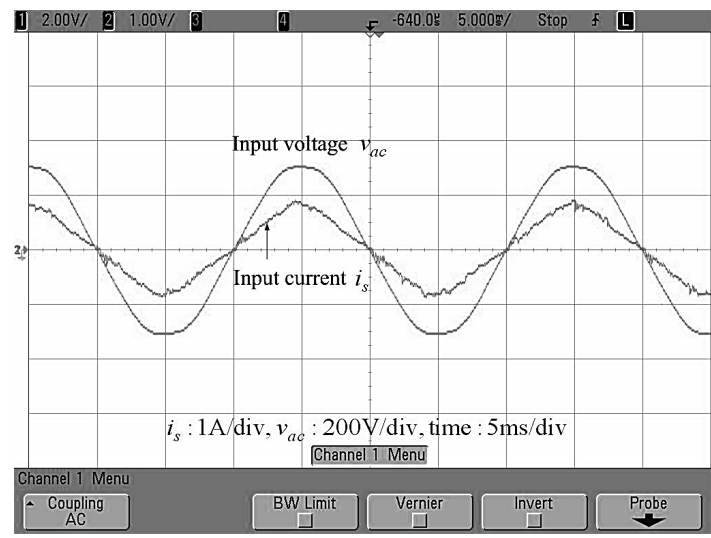

Fig. 25. The input current and input voltage of the AC/DC converter controlled by the PI controller with the power balance control technique.

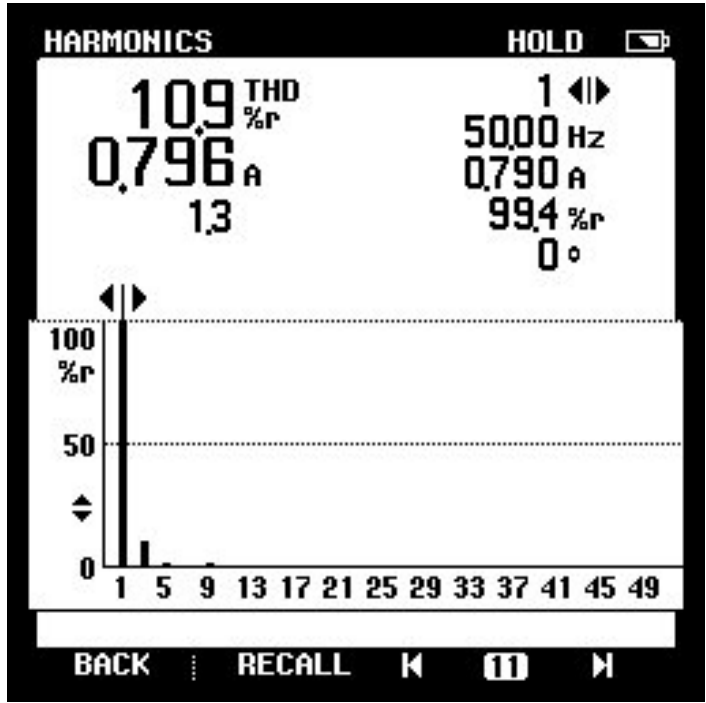

Fig. 26. The harmonics content of the input current in Fig. 25

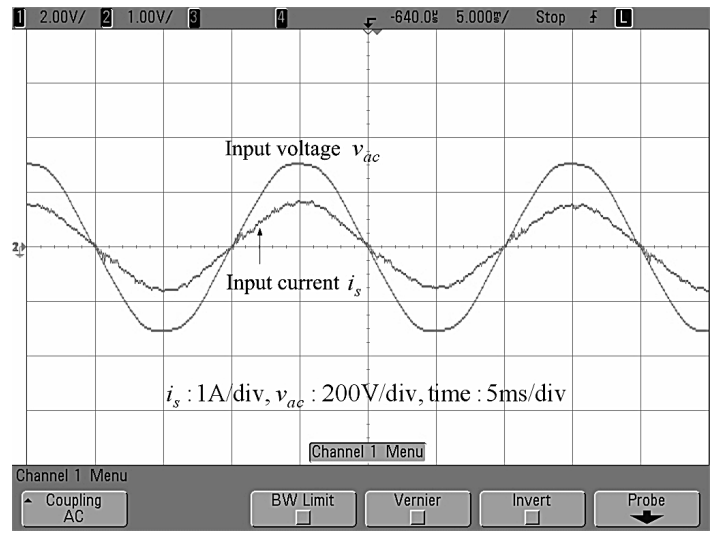

Fig. 27. The steady state of the input current and the input voltage of the AC/DC converter controlled by the proposed method.

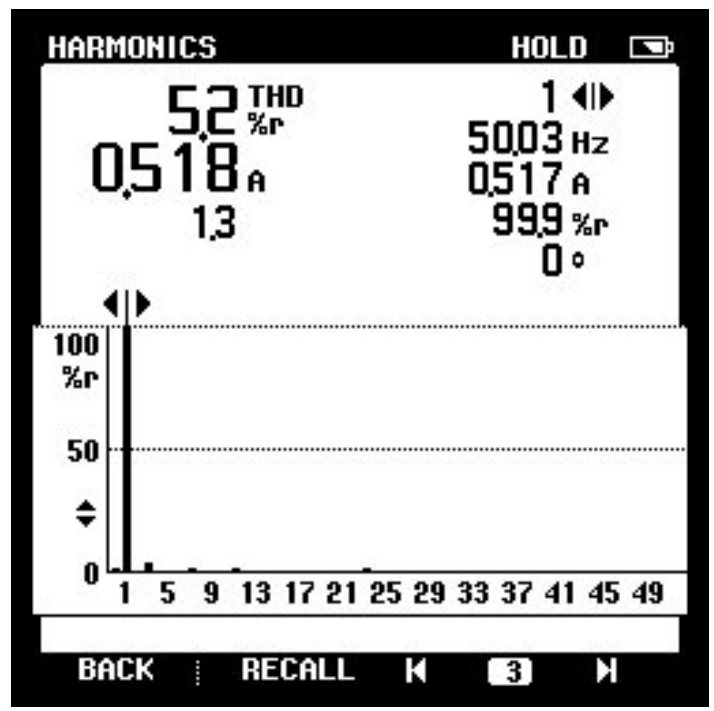

Fig. 28. The input current harmonics of the AC/DC converter with $100 \mathrm{~W}$ load controlled by the proposed method. 


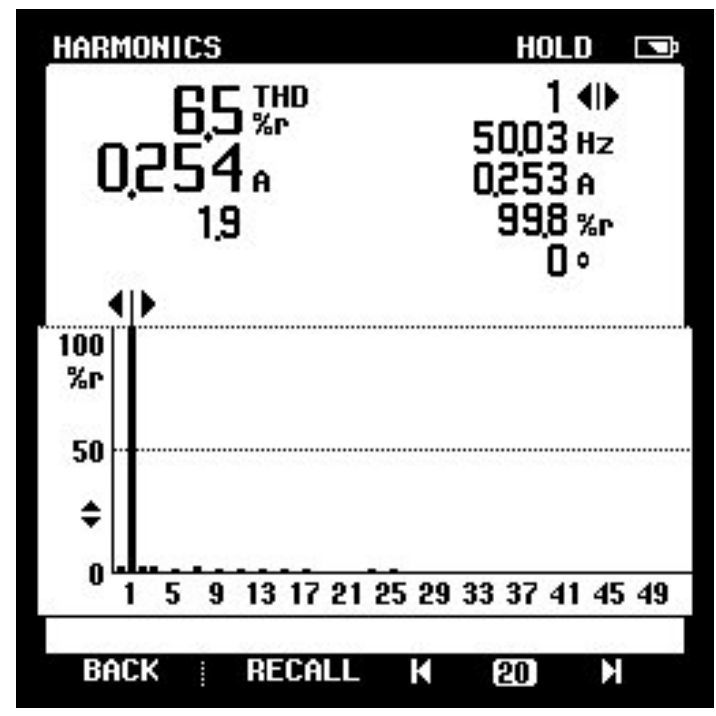

Fig. 29. The input current harmonics of the AC/DC converter with $55 \mathrm{~W}$ load controlled by the proposed method.

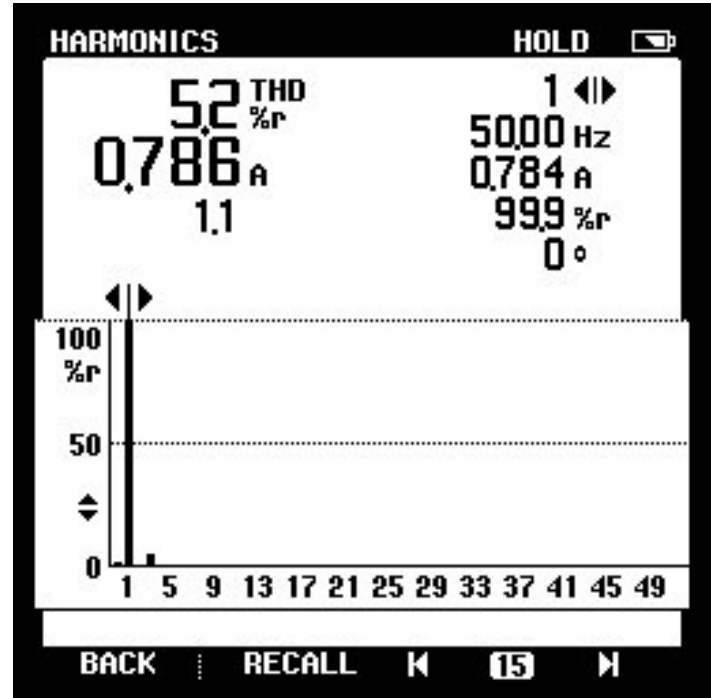

Fig. 30. The input current harmonics of the AC/DC converter with $150 \mathrm{~W}$ load controlled by the proposed method.

\section{REFERENCES}

[1] K. de Gusseme, D. M. Vande Sype, A. P. Van den Bossche, and J. A. Melkebeek, "Digitally controlled boost power-factor-correction converters- operating in both continuous and discontinuous conduction Mode," IEEE Trans. Ind. Electron., Vol. 52, No. 1, pp. 88-97, Feb. 2005.

[2] K. de Gusseme, W. R. Ryckaert, D. M. Vande Sype, J. A. Ghijselen, J. A. Melkebeek, and L. Vandevelde, "A boost PFC converter with programmable harmonic resistance," IEEE Trans. Ind. Appl., Vol. 43, No. 3, pp. 742-750, May/Jun. 2007.

[3] Z. Z. Ye and M. M. Jovanovic, "Implementation and performance evaluation of DSP based control for constant frequency discontinuous conduction mode boost PFC front end," IEEE Trans. Ind. Electron., Vol. 52, No. 1, pp. 98-107, Feb. 2005.

[4] W. Zhang,Y. Fei Liu, and B. Wu, "A new duty cycle control strategy for power factor correction and FPGA implementation," IEEE Trans. Power Electron., Vol. 21, No. 6, pp.1745-1753, Nov. 2006.

[5] K.Yao, X. Ruan, X. Mao, and Z. Ye, "DCM boost pfc converter with high input PF," in Proc. of $25^{\text {th }}$ IEEE APEC 2010, pp. 1405-1412, 2010
[6] [6] []B.-H. Lee, C.-E. Kim, K.-B. Park, and G.-W. Moon, "A new singlestage $\mathrm{pfc}$ ac/dc converter with low link-capacitor voltage," Journal of Power Electronics, Vol. 7, No. 4, pp. 328-335, Oct. 2007.

[7] [7] []E. H. Ismail, "Bridgeless sepic rectifier with unity power factor and reduced conduction losses," IEEE Trans. Ind. Electron., Vol. 56, No. 4, pp.1147-1157, Apr. 2009.

[8] X. Yang, Y. Ying, and W. Cheny, "A novel interleaving control scheme for boost converters operating in critical conduction mode," Journal of Power Electronics, Vol. 7, No. 4, pp. 271-277, Oct. 2007.

[9] J.-R. Tsai , T.-F. Wu , C.-Y. Wu , Y.-M. Chen, and M.-C. Lee, "Interleaving phase shifters for critical-mode boost PFC", IEEE Trans. Power Electron., Vol. 23, No. 3, pp.1348-pp.1357, May 2008.

[10] K.-T. Kim, W.-Y. Choi, J.-M. Kwon, and B.-H. Kwon, "A singlestage AC/DC converter with low voltage stresses and reduced switching losses," Journal of Power Electronics, Vol. 9, No. 6, pp. 823-834, Nov. 2009.

[11] A. Fernandez, J. Sebastian, P. Villegas, M. M. Hernando, and D. G. Lamar, "Dynamic limits of a power-factor preregulator," IEEE Trans. Ind. Electron., Vol. 52, No. 1, pp. 77-87, Feb. 2005.

[12] A. Prodic, J. Chen, D. Maksimovic, and R.W. Erickson, "Self-tuning digitally controlled low-harmonic rectifier having fast dynamic response," IEEE Trans. Power Electron., Vol. 18, No. 1, pp.420-428, Jan. 2003.

[13] P. Mattavelli, G. Spiazzi, and P. Tenti, "Predictive digital control of power factor preregulators with input voltage estimation using disturbance observers," IEEE Trans. Power Electron., Vol. 20, No. 1, pp.140147, Jan. 2005.

[14] A. Prodic, D. Maksimovic, and R. W. Erickson, "Dead-zone digital controllers for improved dynamic response of low harmonic rectifiers," IEEE Trans. Power Electron., Vol. 21, No. 1, pp. 173-181, Jan. 2006.

[15] A. Prodic, "Compensator design and stability assessment for fast voltage loops of power factor correction rectifiers," IEEE Trans. Power Electron., Vol .22, No. 5, pp.1719-1730, Sep. 2007.

[16] U. Kamnarn and V. Chunkag, "Power balance control technique of the modular three-phase AC to DC converter with fast transient response," ARTICLE Electric Power Systems Research, Vol. 77, No. 12, pp.15851594 , Oct. 2007.

[17] D. S. L. Simonetti, J. Sebastian, F. S. dos Reis, and J. Uceda, "Design criteria for SEPIC and CUK converters as power factor preregulators in discontinuous conduction mode," in Proc. IEEE PEMC Conf., pp. 283-288, 1992.

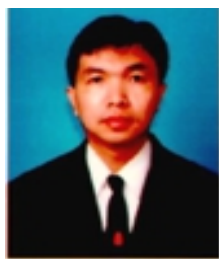

Pisit Wisutmetheekorn was born in Angthong, Thailand, on May 11, 1970. He received his B.S. (1st Class Honors) in Industrial Electrical Technology and his M.E. in Electrical Engineering from King Mongkut's Institute of Technology North Bangkok (KMITNB), Bangkok, Thailand, in 1993 and 1998, respectively. $\mathrm{He}$ is currently pursuing his Ph.D. at King Mongkut's University of Technology North Bangkok (KMUTNB). His current research interests are in the areas of control applications, power electronic circuits, electrical motor drives, and automation systems.

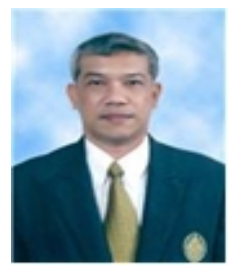

Viboon Chunkag was born in Nonthaburi, Thailand, on February 3, 1957. He received his B.S. (Honors) in Electrical Engineering from King Mongkut's Institute of Technology North Bangkok (KMITNB), Bangkok, Thailand, in 1979, his M.S. in Electrical Engineering from Kasetsart University, Bangkok, Thailand, in 1985, and his Ph.D. from the School of Electrical and Electronic Engineering, University of Bath, Bath, U.K., in 1995. Since 1980, he has been with King Mongkut's Institute of Technology North Bangkok (KMITNB), which was changed to King Mongkut's University of Technology North Bangkok (KMUTNB) in December 2007. He is currently an Associate Professor in the Department of Electrical Engineering, Faculty of Engineering, KMUTNB. His current research interests include the analysis of power electronic circuits and control, rectifiers and power factor correction, power system harmonics, power switching converters, active power filters, etc. 